Boise State University

ScholarWorks

7-1-2009

\title{
American Kestrel Reproduction: Evidence for the Selection Hypothesis and the Role of Dispersal
}

\author{
Karen Steenhof \\ Boise State University \\ Julie A. Heath \\ Boise State University
}




\title{
American Kestrel Reproduction: Evidence for the Selection Hypothesis and the Role of Dispersal
}

\author{
Karen Steenhof and Julie A. Heath \\ Boise State University
}

\begin{abstract}
Many hypotheses attempt to explain why younger, less experienced birds have relatively low reproductive output. We evaluated reproductive patterns of marked American Kestrels Falco sparverius nesting in boxes in southwestern Idaho from 1992 to 2006 to test predictions of these hypotheses. Results were consistent with the selection (differential mortality) hypothesis and did not support the constraint, restraint or recruitment hypotheses. Most known-age Kestrels nested in their first year of life, and there was no apparent short-term or long-term reproductive advantage to delayed breeding. The number of years that Kestrels nested in study area boxes ranged from 1 to 6 years, with most Kestrels nesting in only 1 year. Reproductive rates were higher for birds with at least 1 year of nesting experience than for birds nesting in boxes for the first time. After 2 years of nesting, reproductive rates leveled off; there was no evidence for additional improvement or for senescence. Differences in reproductive output with experience/age were due to variation among and not within individuals. Individuals that nested in more than 1 year had similar reproductive rates in their first and second years. Poor producers either died or dispersed after 1 year of nesting in study area boxes. Successful females that nested early in the season and successful males that had been produced locally had the highest probability of returning to nest in a subsequent year.
\end{abstract}

Keywords: age, experience, Falco sparverius, life history, population dynamics, raptor, reproductive success

Age-specific patterns of survival and reproduction are important in understanding behavioural strategies, life histories, population dynamics and evolutionary ecology (Forslund \& Pärt 1995), and they are also relevant to population management and conservation (Martin 1995). Survival and reproduction vary with the age and experience of individuals in most bird species (Martin 1995), with age accounting for much of the total variation in reproductive success among individuals (Village 1986, Forslund \& Pärt 1995). In most bird species, productivity increases with experience, and some species exhibit reduced productivity associated with senescence in later years (e.g., Newton \& Rothery 1998, 2002, Nielsen \& Drachmann 2003). The reproductive output of first-time breeders tends to be lower than that of more experienced individuals in many species (Forslund \& Pärt 1995, Low et al. 2007). Hypotheses (Table 1) to explain why younger breeders have low reproductive output (Forslund \& Pärt 1995, Martin 1995, Mauck et al. 2004, Low et al. 2007) include: 1) optimization of reproductive effort with increased reproductive investment in later years as the residual reproductive value declines (the restraint or effort hypothesis), 2) age-related improvements in competence (the constraint or experience hypothesis), 3) the progressive appearance of good producers that delay their first breeding (the recruitment hypothesis) and 4) the progressive disappearance of poorly producing individuals (the selection or differential mortality hypothesis). The last hypothesis suggests that poor breeders die at a younger age than better breeders. However, disappearance of inferior breeders from open populations in a finite study area may be due to either mortality or dispersal (Haas 1998, Bregnballe 2006).

The predictions of the four hypotheses are not mutually exclusive (Forslund \& Pärt 1995, Laaksonen et al. 2002; Table 1), and some studies have found evidence for more than one explanation in the same population (Nol \& Smith 1987, Espie et al. 2000, Laaksonen et al. 2002, Reid et al. 2003, Bregnballe 2006, Low et al. 2007). The restraint and recruitment hypotheses predict high rates of delayed breeding within 
populations and higher longevity or lifetime reproduction for individuals that delay breeding. The restraint and constraint hypotheses predict that individuals improve their reproductive output as they age, whereas the selection hypothesis predicts that older cohorts have higher reproductive output only because poor producers disappear from the nesting population at a young age. Thus, differences in reproductive output within individuals as they age would provide evidence for the constraint or restraint hypotheses, whereas differences among individuals would support the selection hypothesis (Newton \& Rothery 1998, Espie $e t$ al. 2000). The constraint hypothesis predicts an inverse relationship between survival and reproductive output in the preceding year, whereas the selection hypothesis predicts a positive relationship between reproductive output and subsequent survival. A positive relationship between longevity and early success, particularly in the first nesting year, would support the selection hypothesis; a negative relationship would support the restraint hypothesis, and no relationship might support the constraint hypothesis (Mauck et al. 2004).

Most studies of birds have shown that individuals improve their reproductive performance with age or that survival is not related to reproductive performance in the previous year (Martin 1995, Nielsen \& Drachmann 2003). Fewer have supported the selection hypothesis (Martin 1995), and even fewer have identified the phenotypic characteristics of inferior breeders that are lost from the population early in life. Support for the selection hypothesis has come from studies of sparrows (Nol \& Smith 1987), seabirds (Wooller et al. 1990, Mauck et al. 2004, Barbraud \& Weimerskirch 2005) and relatively small, short-lived raptors. Eastern Screech-owl Otus asio females that survived to nest in more than 1 year had higher nesting success rates in their first year than female owls that nested only once (Gehlbach 1989). Age-specific variation in Merlin Falco columbarius reproduction was probably due to a combination of disproportionate mortality of inferior female breeders and improved competency of males with experience (Espie et al. 2000). Male Tengmalm's Owls Aegolius funereus that nested late were less likely to survive and return during the decrease phase of the vole cycle (Laaksonen et al. 2002). At least three studies have suggested that late dates of clutch initiation are a characteristic of poor producers that disappear (Espie 2000, Laaksonen et al. 2002, Low et al. 2007). One reason for late nesting might be late pairing (Village 1985). In populations where some individuals are year-round residents, locally produced residents may have an advantage over migrants or immigrants in securing nesting territories, obtaining mates and initiating nesting attempts early in the nesting season.

In this paper we examined whether reproductive output was related to age, years of nesting experience, or natal origin in a population of marked American Kestrels Falco sparverius nesting in boxes in southwestern Idaho. American Kestrels are small, socially monogamous and sexually dimorphic raptors that occur throughout North and South America (Smallwood \& Bird 2002). They occur commonly in habitats used and modified by humans and, as secondary cavity nesters, they readily use nestboxes. Males provide most of the food for females during courtship, incubation and early brood-rearing, and both adults provide food to nestlings older then 10 days of age (Balgooyen 1976). In southwestern Idaho, Kestrels have a prolonged nesting season (March-August), and many, if not most, individuals remain on the nesting grounds through the winter (Henny \& Brady 1994, K. Steenhof, unpubl. data). Yearling males may acquire territories as early as the autumn of their hatching year (Smallwood \& Smallwood 1998, K. Steenhof, unpubl. data,). We evaluated reproduction and longevity for 89 breeding Kestrels (55 males and 34 females) marked as nestlings in or near study area boxes ('known-age' birds that could be considered local recruits) and 893 (355 males, 538 females) individuals first encountered as adults nesting in boxes from 1992 to 2005 ('unknown-age' birds, which had not been produced in study area boxes). We tested hypotheses that attempt to explain age-specific differences in reproduction, and we identified factors associated with the probability of Kestrels returning to nest in more than 1 year.

\section{Methods}

The study area included nest boxes in southwestern Idaho $\left(43^{\circ} \mathrm{N} 116^{\circ} \mathrm{W}\right)$ that had been erected from 1986-1992. Approximately 20\% of boxes were on signs along an interstate highway, 20\% were on trees in rural residential properties near Kuna, and $60 \%$ were wooden poles in agricultural and exurban areas south of Boise and Meridian. The irregularly shaped study area encompassed approximately $1000 \mathrm{~km}^{2}$ and was approximately $65 \mathrm{~km}$ long on its longest axis (northwest-southeast) and $22 \mathrm{~km}$ wide. Nearest neighbor distances between boxes averaged $886 \pm 43 \mathrm{~m}$ (range: 178-2574 m). Old trees and buildings occurred 
throughout the study area, so the nest boxes we monitored were not the only locations where Kestrels could nest within the study area. In addition, other investigators erected nestboxes within and on the periphery of our study area from 1998 to 2002.

Our field procedures followed Animal Care Protocol guidelines approved by Boise State University (IACUC Numbers 006-01-006 and 006-05-004). Each year from 1986 to 2006, we checked, cleaned and added fresh wood-shavings to all boxes in March, and each year we replaced and repaired some boxes. We re-visited all boxes in April, May and June to check for occupancy, and we removed nests of European Starlings Sturnus vulgaris to keep boxes suitable for Kestrels. We re-visited boxes with Kestrel eggs or young as often as necessary to capture adults, estimate ages of young and ascertain nesting success and number of young produced. We caught most adults while they were incubating in boxes. At sites where we had been unable to catch adults in boxes during incubation or early brood-rearing, we used a mist-net with a live Great Horned Owl Bubo virginianus during late brood-rearing (Steenhof et al. 1994).

We banded nestlings and unmarked adults with aluminum USGS bands and recorded band numbers of adults that already had bands. We assigned median hatching dates to all broods based on the ages of nestlings estimated from a photographic ageing key (Griggs \& Steenhof 1993). We used nest discovery dates (dates when eggs were first found) as an index to nest initiation dates because they correlated well with hatching dates $(r=0.89, n=577, P<0.001)$. To account for variation in breeding chronology among years, we calculated a standardized nest initiation date by dividing the date eggs were found by the median date that all first clutches were found in the same year. We considered nesting attempts to be successful when young reached $80 \%$ of fledging age (75\% feathered or approximately 22 days; Griggs \& Steenhof 1993). Mean nesting success was calculated separately for each gender and was defined as the proportion of individuals that produced at least one young that reached 22 days of age. We considered broods with young $>22$ days to be the number of young that fledged. Most young were banded at 23-25 days of age. We excluded broods from analyses if counts were incomplete or if they were based on counts of young before they reached 22 days of age. We did not assess nesting success or productivity in 2006, the final year of our study. We defined local lifetime reproduction of a bird to be the number of fledgingage young produced in all years that the individual nested in study area boxes. We excluded individuals that were still nesting in 2006 from estimates of local lifetime reproduction. We also excluded individuals from assessments of lifetime reproduction if we had incomplete information on their nesting success or brood size at fledging in one or more years that they nested in boxes. Although we banded some adults and most nestlings in boxes from 1986 to 1991, we did not make a concerted effort to capture all adults until 1993. Therefore, our analyses include only those individuals marked or re-encountered in 1992 or later.

We considered only known-age nesters to assess the frequency of delayed breeding in Kestrels and compared age at first known nesting by gender using a likelihood ratio test (G-test; Sokal \& Rohlf 1998). We compared nest initiation dates, numbers of eggs laid and number of fledglings produced by birds that began nesting in their first year after hatching to birds that began nesting in the second or third year after hatching with nonparametric Wilcoxon 2-sample tests. We compared nesting success of these two groups using likelihood ratio tests, and we used Wilcoxon 2-sample tests to compare their breeding longevity and lifetime reproduction.

We evaluated how reproductive rates varied with years of nesting experience for all nesting adults in the sample using a generalized linear model (GLMM) with bird included as a repeated subject. This analysis detected differences among cohorts of birds but did not model intra-individual changes. We grouped birds with 3, 4 and 5 years of experience in the category $3+$ years of nesting experience and performed separate analyses for males and females. We used different null distributions for each response variable. Nest initiation dates fit a normal distribution; we used a logit-link function with a binomial distribution to analyse nesting success; and we used a log-link function with a Poisson distribution to analyse numbers of eggs and fledglings produced. We used paired $t$-tests to assess within-bird differences in reproduction over time, comparing reproduction of individuals in their first and second years of nesting. We used logistic regressions to examine factors that affected the probability of male and female Kestrels returning to nest in a study area box after 1 year of nesting. Descriptive statistics are reported as mean \pm se. 


\section{Results}

Of 944 Kestrels that nested in boxes from 1992 to 2005, 780 (83\%) were encountered nesting in only 1 year. Excluding birds still nesting in 2006, 393 males nested for an average of $1.3 \pm 0.04$ years, and 551 females nested for $1.2 \pm 0.03$ years (Table 2). One male and one female nested in study area boxes for 6 years between 1992 and 2005. The observed lifespan of Kestrels nesting in boxes, defined as the difference between year of hatching and year of last known nesting, ranged from 1 to 6 years for known-age males and 1 to 3 years for known-age females. The minimum lifespan for unknown-age birds, defined as the difference between year of first known nesting and year of last known nesting +1 , ranged up to 7 years for males. A female at least 8 years old was still nesting in 2006, the final year of our study.

\section{The Frequency and Consequences of Delayed Reproduction}

Most Kestrels that we had banded as nestlings and re-captured as breeding adults nested in their first year after hatching. The difference between sexes (88\% of 56 males and $82 \%$ of 34 females) was not significant $\left(G_{2}=0.45, P=0.51\right)$. Ten per cent first nested in study area boxes during their second year. One female and three males were not encountered nesting in boxes until their third year. Because we did not capture all Kestrels nesting in boxes, some apparent first time nesters might have bred in the area in previous years without being detected (Wyllie \& Newton 1991). Alternatively, some may have bred elsewhere in their first or second year. Thus the observed rate of nesting in the first year should be considered a minimum.

Kestrels that nested in study area boxes for the first time as 2- or 3- year olds had similar nest initiation dates and they produced similar numbers of eggs and fledglings as Kestrels that nested as yearlings (Table 3). Patterns were similar for both sexes (all $P>0.09$ ). Nesting success rate of 2- and 3-year olds nesting in boxes for the first time (54\%) was lower than that of Kestrels nesting as yearlings $\left(84 \% ; G_{1}=4.2, P=\right.$ $0.04)$, and lower than those of 2-year-olds nesting in boxes for the second time $\left(81 \% ; G_{1}=9.3, P=0.002\right)$. Mean number of years that Kestrels nested in study area boxes did not differ with age at first known nesting, and age at first known nesting was unrelated to local lifetime reproduction (Table 3).

\section{Reproductive Rates and Nesting Experience}

Female American Kestrels in their first known year of nesting produced fewer eggs and fledglings than those with one or more years of nesting experience in the study area (Fig. 1a, 1b). Nesting success rates were higher for individuals with at least 1 year of experience than for first time nesters (Fig. 1c). After 2 years of nesting, success rates and productivity of females leveled off (Fig. 1b, 1c). There was no evidence for decreased productivity in older birds, and there was no clear improvement in nesting success and number of young fledged after 2 years of nesting. Three of four females with 4 or 5 years of experience nested successfully. Nest initiation dates did not vary with number of years of nesting experience in females $\left(F_{3,129}=2.04, P=0.11\right)$.

The number of fledglings produced was related to the number of years that males had nested (Fig. 1b), but the number of eggs produced by their mates was unrelated to male nesting experience (Fig. 1a). Nesting success rates were higher for males with at least 1 year of experience than for first-time nesters (Fig. 1c). After 2 years of nesting, success rates and productivity of males levelled off (Fig. 1b, 1c). There was no evidence for decreased productivity in older birds, and there was no clear improvement in nesting success and number of young fledged after 2 years of nesting. All males with 4 or 5 years of experience $(n=5)$ nested successfully. Nest initiation dates did not vary with number of years of nesting experience in males $\left(F_{3,121}=1.13, P=0.34\right)$.

Paired tests on birds that nested in the study area in more than 1 year showed that the number of young fledged by individual Kestrels in their first year of nesting did not differ from the number fledged in their second year (males: $t_{78}=1.1, P=0.28$; females: $t_{87}=0.77, P=0.45$ ). Nest initiation dates did not change between the first and second year of nesting for males $\left(t_{95}=0.43, P=0.67\right)$ or females $\left(t_{97}=0.90, P=\right.$ 0.37). Females laid similar numbers of eggs in their first and second known years of nesting $\left(t_{96}=0.76, P\right.$ $=0.45)$, and mates of males laid similar numbers of eggs in the male's first and second year of nesting $\left(t_{95}\right.$ $=0.43, P=0.67)$. 


\section{Factors Associated with the Probability of Nesting in Multiple Years}

Females were more likely to die or disperse $(83 \%)$ from study area boxes after their first nesting season than were males ( $\left.76 \% ; G_{1}=5.8, P=0.016\right)$. Kestrels of both genders that failed in their first nesting attempt were more likely to die or disperse by the following nesting season (Table 4). Successful females were 4.9 times (CI: 2.5 - 9.7) more likely to return than unsuccessful females, and male Kestrels were 2.3 times (CI: 1.2 - 4.4) more likely to return if they were successful the first year. Birds that failed in their first year nested in boxes for fewer years (mean $=1.1$ years, $n=269$ ) than birds that nested successfully in their first year (mean $=1.4$ years, $n=700$, Wilcoxon $Z=5.13, P<0.001$ ). This difference was due mainly to birds dying or dispersing after the first nesting year. Among Kestrels that nested in the study area for at least 2 years, number of years nesting did not differ between Kestrels that nested successfully in the first year (mean $=2.6$ years, $n=171$ ) and Kestrels that failed in their first year (mean $=2.5$ years, $n=$ 23, Wilcoxon $Z=2271, P=0.896$ ).

Other factors associated with whether a bird would return to nest in study area boxes differed for female and male Kestrels. The probability of a female Kestrel returning to nest in a second year was related inversely to her nest initiation date (Table 4). Early nesting females were more likely to return than later nesters. For every unit (standardized day) decrease in nest initiation date, the odds of a female returning increased by 0.17 times (CI: 0.04 - 0.78). Known-age females (local recruits) and unknown-age females returned at similar rates (Table 4). In contrast, males that had hatched in study area boxes were 5.3 times (CI: 2.9 - 9.8) more likely to nest in a second year than males hatched elsewhere (Table 4).

\section{Discussion}

We found no evidence to support the restraint or recruitment hypotheses. Most Kestrels bred as yearlings, and age at first nesting was unrelated to breeding lifespan or local lifetime reproduction. In other species, individuals tend to breed at an early age when prey is especially abundant or when numbers of older birds are low (Newton 1979:123, Steenhof et al. 1983). For example, age at first breeding in Eurasian Sparrowhawks Accipiter nisus was lower in populations that were increasing after being reduced by organochlorine pesticides (Wyllie \& Newton 1991). Because Kestrels are relatively short-lived, the number of older individuals is always low, and it is advantageous for birds to try to raise as many young as possible in their first year.

We found no evidence to support the constraint hypothesis. The probability of surviving and returning to nest in a second year was positively related to reproductive output in the previous year, and individuals that did return had similar reproductive rates in their first and second years of nesting. We found no evidence that individual Kestrels became more productive with age or additional years of breeding experience.

Our results were consistent with predictions of the selection hypothesis. Differences in Kestrel reproduction associated with years of nesting experience were related mainly to differences among individuals rather than differences within individuals. Longevity, as measured by the number of years nesting, was positively related to nesting success in the first year. This suggests that higher productivity of experienced birds was due to fewer poorly producing and unsuccessful birds in the experienced sample rather than individual increases in productivity associated with age or experience.

Our results differ from studies of many other raptors including Eurasian Sparrowhawks, Northern Goshawks Accipiter gentilis and Tengmalm's Owls (Newton \& Rothery 1998, 2002; Laaksonen et al. 2002, Nielsen \& Drachmann 2003), which showed that individuals improved their reproductive performance as they aged. American Kestrels appear similar to Merlins in that higher quality individuals (i.e., those that produced most young) were more likely to survive and return the year following their first breeding season, and the disappearance of less productive individuals resulted in higher average production of experienced birds (Espie et al. 2000).

Most studies that have confirmed differential mortality as important in explaining age-dependent reproduction have involved closed populations that nest on islands (e.g., Nol \& Smith 1987, Barbraud \& Weimerskirch 2005, Low et al. 2007). However, American Kestrels that nested in southwestern Idaho 
were free to move to adjacent areas or other substrates within the study area. Thus Kestrels that disappeared may have died or they may have dispersed from study area boxes to find other nesting opportunities elsewhere. In most cases, it is difficult if not impossible to distinguish mortality from dispersal (Haas 1998).

Unsuccessful birds may be more likely to die (Pugasek \& Diem 1990) or disperse (Haas 1998) after their first nesting season. Dispersing after failure may be advantageous. A greater tendency to disperse after nesting failure has been demonstrated in many birds, including raptors (Newton \& Marquiss 1982, Beletsky \& Orians 1987, Pärt \& Gustafsson 1989, Village 1990, Newton 1993, Haas 1998, Forero et al. 1999). There is less evidence for increased mortality of raptors that nest unsuccessfully. Gender differences suggest many American Kestrels that disappear after their first nesting season probably disperse rather than die. Male Kestrels were more likely to nest in $>1$ year than females, supporting Greenwood's (1980) resource competition hypothesis that females disperse to acquire mates and males are more philopatric to increase their chances of acquiring a territory (Johnson \& Gaines 1990). If male American Kestrels have similar survival rates as females, then differential dispersal of the sexes may have been more important than differential mortality in this population.

The fact that locally produced males were five times more likely to nest in a second year than males produced elsewhere also suggests that differential dispersal may be as important as differential mortality for Kestrels. Few of the nesting adults in the Kestrel population had been raised locally in boxes, consistent with the fact that most local avian nesting populations consist mainly of immigrants (Lambrechts et al. 1999, Martin et al. 2000). However, locally produced males tended to stay in the area even after nesting failure, suggesting that the tendency for natal dispersal may be related to the tendency for breeding dispersal in male Kestrels. Familiarity with resources within a nesting area may be critically important for the sex that defends the territory and provides most of the food for nestlings (Greenwood 1980). The sex that defends the territory and its resources would be more likely to be philopatric, and the sex that selects the mate would be more likely to disperse. For birds that nest in cavities, the nest site is an important resource that may affect a male's mating and subsequent nesting success. We suggest that disappearance of males, especially locally produced males, was due mostly to mortality and not to dispersal, whereas the disappearance of females was due to a combination of dispersal and mortality.

This study began as a co-operative effort between the Idaho Department of Fish and Game, the Idaho Department of Transportation and the Boise District Bureau of Land Management. Funding in recent years was provided by U.S. Geological Survey Forest and Rangeland Ecosystem Science Center and Boise State University. The study could not have been completed without the dedicated work of Brit Peterson, who collected much of the data as principal field technician. We thank Jim Bednarz, George Carpenter, Craig Groves and Michelle Drysdale, who were instrumental in getting the study started. We also thank Leah Dunn and Erica Schutter who worked as technicians and to numerous individuals who volunteered their time. We are especially indebted to the landowners who graciously allowed us to set up and check boxes on their property. The National Geographic Society donated a ladder to the study. We thank Nate Chelgren who conducted preliminary analyses that provided important insights, and we thank Laura Bond for assistance with the SAS code. Chuck Henny, Carl Marti, Matthias Leu and two anonymous reviewers commented on earlier drafts of the manuscript and provided helpful suggestions. 


\section{References}

Balgooyen, T.G. 1976. Behavior and ecology of the American Kestrel (Falco sparverius L.) in the Sierra Nevada of California. Univ. of Calif. Publ. Zool. 103: 1-83.

Barbraud, C. \& Weimerskirch, H. 2005. Environmental conditions and breeding experience affect costs of reproduction in Blue Petrels. Ecology 86: 682-692.

Beletsky, L.D. \& Orians, G.H. 1987. Territoriality among male Red-winged Blackbirds. I. Site fidelity and movement patterns. Behav. Ecol. and Sociobiol. 20: 21-34.

Bregnballe, T. 2006. Age-related fledgling production in Great Cormorants Phalacrocorax carbo: influence of individual competence and disappearance of phenotypes. J. Avian Biol. 37: 149-157.

Espie, R.H.M., Oliphant, L. W., James, P.C., Warkentin, I.G. \& Lieske, D.J. 2000. Age-dependent breeding performance in Merlins (Falco columbarius). Ecology 81: 3404-3415.

Forero, M.G., Donázar, J.A., Blas, J. \& Hiraldo, F. 1999. Causes and consequences of territory change and breeding dispersal distance in the Black Kite. Ecology 80: 1298-1310.

Forslund, P. \& Pärt, T. 1995. Age and reproduction in birds-hypotheses and tests. Trends Ecol.Evol. 10: 374-378.

Gehlbach, F.R. 1989. Screech-owl. In Newton, I. (ed), Lifetime Reproduction in Birds: 315-326. San Diego, CA: Academic Press. .

Greenwood, P. J. 1980. Mating systems, philopatry and dispersal in birds and mammals. Anim. Behav. 28: 1140-1162.

Griggs, G.R. \& Steenhof, K. 1993. Photographic Guide for Aging Nestling American Kestrels. Boise, ID: U.S. Department of the Interior and Bureau of Land Management.

Haas, C.A. 1998. Effects of prior nesting success on site fidelity and breeding dispersal: an experimental approach. Auk 115: 929-936.

Henny, C.J. \& Brady. G.L. 1994. Partial migration and wintering localities of American Kestrels nesting in the Pacific Northwest. North West. Nat. 75: 37-43.

Johnson, M.L. \& Gaines, M.S. 1990. Evolution of dispersal: theoretical models and empirical tests using birds and mammals. Annu. Rev. Ecol. Syst. 21: 449-480.

Laaksonen, T., Korpimäki, E. \& Hakkarainen, H. 2002. Interactive effects of parental age and environmental variation on the breeding performance of Tengmalm's Owls. J. Anim. Ecol. 71: 2331.

Lambrechts, M.M., Blondel, J., Caizergues, A., Dias, P.C., Pradel, R. \& Thomas, D.W. 1999. Will estimates of lifetime recruitment of breeding offspring on small-scale plots help us to quantify processes underlying adaptation? Oikos 86: 147-151.

Low, M., Pärt, T. \& Forslund, P. 2007. Age-specific variation in reproduction is largely explained by the timing of territory establishment in the New Zealand Stitchbird Notiomystis cincta. J. Anim. Ecol. 76: 459-470.

Martin, K. 1995. Patterns and mechanisms for age-dependent reproduction and survival in birds. Am. Zool. 35: 340-348.

Martin, K., Stacey, P. B. \& Braun, C. E. 2000. Recruitment, dispersal, and demographic rescue in spatially-structured White-tailed Ptarmigan populations. Condor 102: 503-516.

Mauck, R. A., Huntington, C. E. \& Grubb, T.C. Jr. 2004. Age-specific reproductive success: evidence for the selection hypothesis. Evolution 58: 880-885.

Newton, I. 1979. Population Ecology of Raptors. Berkhamstead: T. \& A.D. Poyser.

Newton, I. 1993. Age and site fidelity in female Sparrowhawks, Accipiter nisus. Anim. Behav. 46: 161168.

Newton, I. \& Marquiss, M. 1982. Fidelity to breeding area and mate in Sparrowhawks Accipiter nisus. J. Anim. Ecol. 51: 327-341.

Newton, I. \& Rothery, P. 1998. Age-related trends in the breeding success of individual female Sparrowhawks Accipiter nisus. Ardea 86: 21-31.

Newton, I. \& Rothery, P. 2002. Age-related trends in different aspects of the breeding performance of individual female Eurasian Sparrowhawks (Accipiter nisus). Auk 119: 735-748.

Nielsen, J.T. \& Drachmann, J. 2003. Age-dependent reproductive performance in Northern Goshawks Accipiter gentilis. Ibis 145: 1-8.

Nol, E. \& Smith, J.N.M. 1987. Effects of age and breeding experience on seasonal reproductive success in the Song Sparrow. J. Anim. Ecol. 56: 301-313. 
Pärt, T. \& Gustafsson, L. 1989. Breeding dispersal in the Collared Flycatcher (Ficedula albicollis): Possible causes and reproductive consequences. J. Anim. Ecol. 58: 305-320.

Pugasek, B.H. \& Diem, K.L. 1990. The relationship between reproduction and survival in known-aged California Gulls. Ecology 71: 811-817.

Reid, J. M., Bignal, E. M, Bignal, S., McCracken, D.I. \& Monaghan, P. 2003. Age-specific reproductive performance in Red-billed Choughs Pyrrhocorax phyrrocorax: patterns and processes in a natural population. J. Anim. Ecol. 72: 765-776.

Smallwood, J.A. \& Bird, D.M. 2002. American Kestrel (Falco sparverius). In Poole, A. \& Gill, F. (eds) The Birds of North America, no. 602:32. Philadelphia: Academy of Natural Sciences; Washington, DC: American Ornithlogists' Union.

Smallwood, P.D. \& Smallwood, J.A. 1998. Seasonal shifts in sex ratios of fledgling American Kestrels (Falco sparverius paulus); the early bird hypothesis. Evol. Ecol. 12: 839-853.

Sokal, R. R. \& F. J. Rohlf, F.J. 1998. Biometry: The Principles and Practice of Statistics in Biological Research. $3^{\text {rd }}$ edn. New York: W. H. Freeman.

Steenhof, K., Kochert, M.N. \& Doremus, J.H. 1983. Nesting of subadult Golden Eagles in southwestern Idaho. Auk 100: 743-747.

Steenhof, K., Carpenter, G.P. \& Bednarz, J.C. 1994. Use of mist nets and a live Great-Horned Owl to capture breeding American Kestrels. J. Raptor Res. 28:194-196.

Village, A. 1985. Spring arrival times and assertive mating of kestrels in south Scotland. J. Anim. Ecol. 54: $857-868$.

Village, A. 1986. Breeding performance of kestrels at Eskdalemuir, south Scotland. J. Zool. 208: 367-378.

Village, A. 1990. The kestrel. Calton: T \& A D Poyser.

Wheelwright, N.T. \& Mauck, R. A. 1998. Philopatry, natal dispersal, and inbreeding avoidance in an island population of Savannah Sparrows. Ecology 79: 755-767.

Wooller, R.D., Bradley, J.S. Skira I.J. \& Serventy, D.L. 1990. Reproductive success of Short-tailed Shearwaters Puffinus tenuirostris in relation to their age and breeding experience. J. Anim. Ecol. 59: $161-170$.

Wyllie, I. \& I. Newton. 1991. Demography of an increasing population of Sparrowhawks. J. Anim. Ecol. 60: 749-766. 
This is an author-produced, peer-reviewed version of this article. The definitive version is available at

http://onlinelibrary.wiley.com/. Copyright restrictions may apply. DOI: 10.1111/j.1474-919X.2009.00930.x

Table 1. Predictions of hypotheses that attempt to explain why older (or more experienced) birds have higher reproductive success.

\begin{tabular}{|c|c|c|c|c|}
\hline \multirow[b]{2}{*}{ Title } & \multirow[b]{2}{*}{ Hypothesis } & \multicolumn{3}{|c|}{ Predictions } \\
\hline & & Improvement is & $\begin{array}{l}\text { Delayed } \\
\text { breeding }\end{array}$ & Reproduction \& survival \\
\hline Restraint & Optimize effort vs. survival probability & Within individual & Yes & Negative relationship \\
\hline Constraint & Improvements in competence & Within individual & No & No relationship \\
\hline Recruitment & Good breeders are recruited & Within cohorts & Yes & $?$ \\
\hline Selection & Poor breeders die or disperse & Within cohorts & No & Positive relationship \\
\hline
\end{tabular}


This is an author-produced, peer-reviewed version of this article. The definitive version is available at http://onlinelibrary.wiley.com/. Copyright restrictions may apply. DOI: 10.1111/j.1474-919X.2009.00930.x

Table 2. Number of years that marked American Kestrels nested in boxes in southwestern Idaho, 19922005.

\begin{tabular}{lrrrrrr}
\hline & \multicolumn{7}{c}{ Number of Years Nesting } \\
& 1 & 2 & 3 & 4 & 5 & 6 \\
\hline Males & 23 & 9 & 6 & 5 & 1 & 1 \\
Known-age & 288 & 45 & 11 & 3 & 1 & 0 \\
$\quad$ Unknown-age & 23 & 3 & 0 & 0 & 0 & 0 \\
Females & 446 & 49 & 20 & 7 & 2 & 1 \\
Known-age & & & & & \\
$\quad$ Unknown-age & & & & & & \\
\hline
\end{tabular}


Table 3. Reproductive rates of American Kestrels that first nested in study area boxes as yearlings compared with those that were first encountered nesting in boxes as 2- or 3-year olds. Nest initiation dates and numbers of eggs and fledglings are compared for the first year of nesting.

\begin{tabular}{lcccc}
\hline & \multicolumn{2}{c}{ Age at First Known Nesting } & & \\
& One Year & Two or Three Years & $U$ & $P$ \\
\hline Nest initiation date (standardized) & $1.04 \pm 0.02(77)$ & $1.04 \pm 0.05(13)$ & 569.5 & 0.81 \\
Total number of eggs & $4.97 \pm 0.13(77)$ & $4.76 \pm 0.41(13)$ & 608 & 0.81 \\
Total number of fledglings & $3.35 \pm 0.24(65)$ & $2.38 \pm 0.66(13)$ & 416.5 & 0.18 \\
Number of years nesting in study area & $1.71 \pm 0.12(77)$ & $1.46 \pm 0.22(13)$ & 536.5 & 0.47 \\
Local lifetime reproduction $^{\mathrm{a}}$ & $6.30 \pm 0.68(64)$ & $3.46 \pm 1.02(13)$ & 372.5 & 0.06 \\
\hline
\end{tabular}

${ }^{a}$ the number of fledging-age young produced in all years that the individual nested in study area boxes, excluding birds still nesting in 2006. 
Table 4. The probability of American Kestrels returning to nest in study area boxes for a second year, as determined by binary logistic regression analysis, by gender. Factors in the model included nesting chronology, nesting success and productivity in the first year of nesting as well as natal origin (whether the individual hatched in a study area box or elsewhere). * indicates a significant difference at $P<0.05$.

\begin{tabular}{|c|c|c|c|c|c|}
\hline Gender & Predictor variable & Estimate $(\beta)$ & S.E. & Wald $\chi^{2}$ & $P$ \\
\hline \multirow[t]{6}{*}{ Female } & Intercept & -0.93 & 0.87 & 1.15 & 0.284 \\
\hline & Success in first nesting year & 1.59 & 0.35 & 20.57 & $<0.0001 *$ \\
\hline & Standardized nest initiation date & -1.77 & & & $0.023 *$ \\
\hline & Origin (local) & & 0.78 & $\begin{aligned} & 5.18 \\
- & \end{aligned}$ & 0.53 \\
\hline & Number of eggs laid & & & - & 0.23 \\
\hline & Number of young fledged & & & - & 0.81 \\
\hline \multirow[t]{6}{*}{ Male } & Intercept & -2.09 & 0.32 & 43.15 & $<0.0001$ \\
\hline & Success in first nesting year & 0.81 & 0.34 & 5.73 & $0.017 *$ \\
\hline & Standardized nest initiation date & - & & & 0.08 \\
\hline & Origin (local) & 1.67 & $\overline{-}$ & 27.85 & $<0.0001 *$ \\
\hline & Number of eggs laid & & & - & 0.90 \\
\hline & Number of young fledged & & & - & 0.59 \\
\hline
\end{tabular}




\section{Figure Legend}

Figure 1. Mean ( \pm s.e.) number of eggs laid (a), number of fledglings produced (b) and nesting success (c) in relation to years of nesting experience of female and male American Kestrels nesting in boxes in southwestern Idaho 1992-2005. Letters to the upper left of symbol represent significant differences within gender. Females with $\geq 1$ year of nesting experience laid significantly more eggs $\left(F_{3,701}=15.45, P=\right.$ $0.0015)$, produced more young $\left(F_{3,670}=19.46, P=0.0002\right)$, and had a higher probability of nesting success $\left(F_{3,697}=14.10, P=0.0028\right)$ than females nesting for the first time. Males with $\geq 1$ year of nesting experience produced significantly more young $\left(F_{3,509}=15.02, P=0.0018\right)$, and had a higher probability of nesting success $\left(F_{3,532}=7.61, P=0.05\right)$ than males nesting for the first time. Years of nesting experience was unrelated to the number of eggs laid by a male's mate $\left(F_{3,534}=4.82, P=0.19\right)$. Sample sizes are to the left of the symbol. 

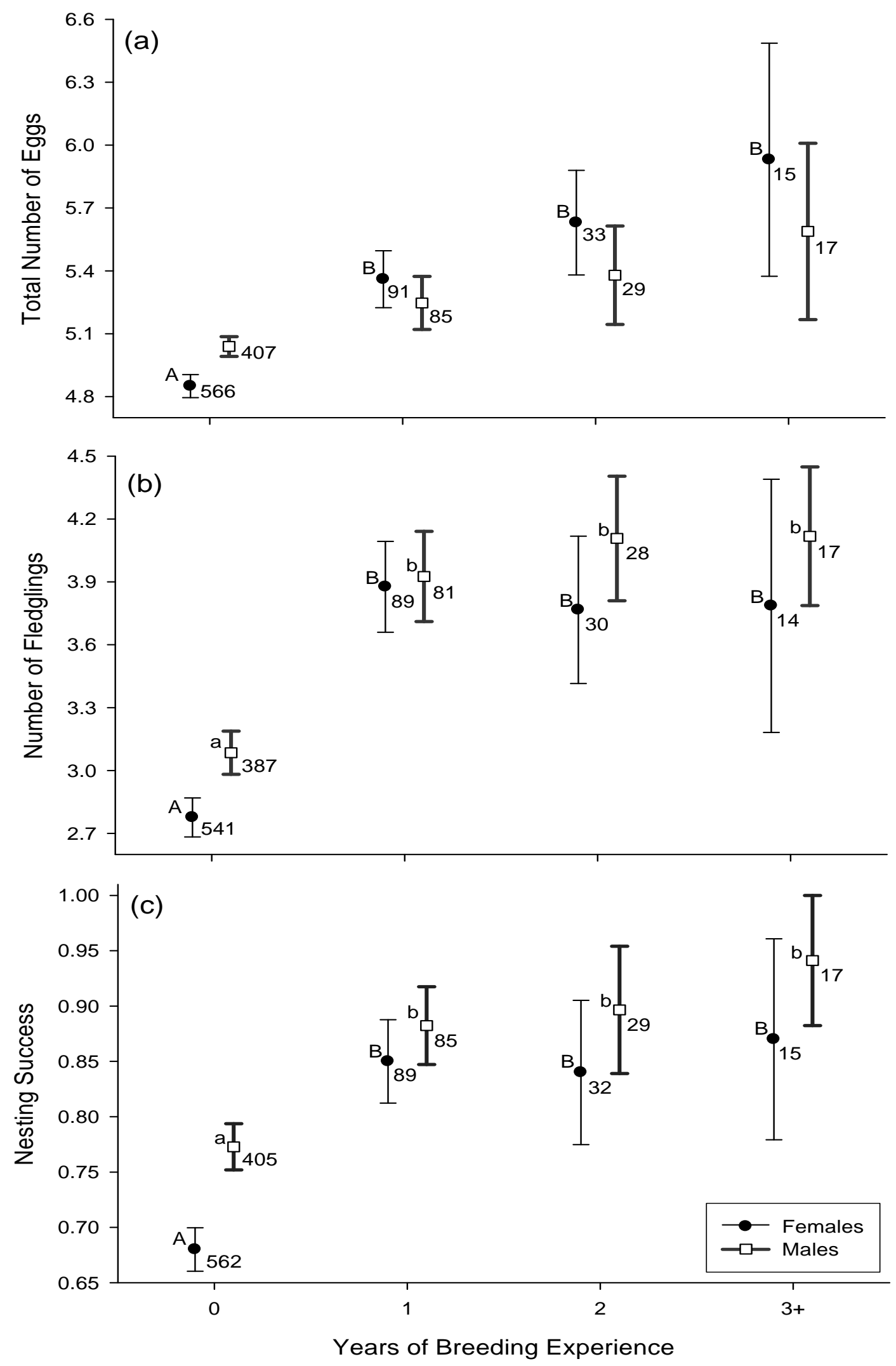